\title{
Challenges and Best Practices for English Language Learners: Extensive Research
}

\author{
Yewulsew Melak \\ Debre Markos University, College of Social Science and Humanities., P.O Box 269, Debre Markos
}

\begin{abstract}
English Language Learners (ELL) face challenges in schools because they often do not receive adequate linguistic support in a typical classroom. These students do not have access to appropriate second language acquisition resources, and therefore they are sometimes misdiagnosed with a cognitive delay. English Language Learners are then placed in a restrictive special education classroom as a disproportionate rate. This research inquiry explored studies published in peer-reviewed journals, revealing that three common obstacles exist for EFL students in non-English speaking nations; these are low self-efficacy, poor attitudes, and narrow teaching strategies. In surmounting these obstacles, reflective journaling emerged as a channel for addressing all three challenges and boosting learner autonomy in accordance with accommodation theory. The greatest gap in the literature is a failure to address any preventative measures for countering low self-efficacy and poor attitudes before they manifest in students. English Language Learners are then placed in a restrictive special education classroom as a disproportionate rate.
\end{abstract}

DOI: $10.7176 / J L L L / 63-04$

Publication date: December $31^{\text {st }} 2019$

\section{Introduction}

English Language in Essays Students learning English as a foreign language (EFL) are presented with a myriad of challenges that significantly affect how efficiently they acquire the language. Nations in which English is not the primary language are increasingly recognising the global nature of English, particularly with respect to professional communications. As the English language becomes more and more paramount in the twenty-first century as a common tongue in the global marketplace, EFL students are charged to surmount the challenges they face learning the language in a non-English speaking nation. This inquiry posits that there are shared problems faced by EFL students in non-English speaking nations, and finding relevant solutions to these problems is essential given the primacy of English as the twenty-first century progresses.

The global spread of English over the last 40 years is remarkable. It is unprecedented in several ways: by the increasing number of users of the language; by its depth of penetration into societies and by its range of functions. According to US Bureau of Educational and Cultural Affairs, in worldwide over 1.4 billion people live in countries where English has official status. One out of five of the world's population speaks English with some degree of competence. And by 2000, one in five- over one billion people- will also be learning English. Over $70 \%$ of the world's scientists read English. About $85 \%$ of the world's mail is written in English. And $90 \%$ of all information in the world's electronic retrieval systems is stored in English. By 2010, the number of people who speak English as a second or foreign language will exceed the number of native speakers (Hasman, 2009). This shows that English is used for more purposes than ever before.

Despite the dominance of English in the global marketplace, only a handful of nations recognize English as an official language (Crystal, 2003). Attitudes regarding English as the proverbial global language vary widely all over the world, with those hailing from English-speaking nations, particularly the United Kingdom and the United States, exhibiting protective feelings over English while EFL students may begrudge the effort required to acquire such a complex language (Crystal, 2003). Moreover, the cultural survival of some nations is being threatened by the focus on English, birthing resentment and anger among EFL students. English has, however, gained status as a global language due to its prevalence around the world, and nations have made choices, both strategic and unwitting, to accept English into their societies (Crystal, 2003).

Accommodation theory asserts that speakers of languages automatically adjust their communicative behaviours due to their roles in the conversation (Crystal, 2003). Accommodating behaviours are generally evident only in face-to-face communication, manifesting as complex, reciprocal mannerisms and expressions that both affect and are affected by attitudes, self-efficacy, and autonomy of the speaker (Nunan, 1998). This theory is applicable to EFL students as it facilitates understanding of why students learning English in a nonEnglish speaking nation may interpret their roles in a specific way in accordance with their non-native English speaking status.

The purpose of this study is to ascertain what common challenges are faced by EFL learners, as this is particularly critical given English's global language status (Crystal, 2003). By extension, the following two research questions are searched:

1. What common challenges are faced by EFL learners in non-English speaking nations? 


\section{How can these challenges by surmounted, if at all?}

\section{Methodology}

In recognising that there are problems faced by EFL students around the world, this researcher pursued the scholarly literature on the topic. Using an electronic library search, literature was selected that was published in peer-reviewed journals within the last five years. The following keywords were used for the search, within the context of peer-reviewed journals published since the year 2006: English as a foreign language, challenges, students, teaching strategies, obstacles, and learning differences. The articles were selected due to their scientific nature, using mixed-method methodologies, and their critical discussion of challenges faced by EFL students in a range of nations around the world.

\section{Results}

The research suggests that there are several common challenges faced by EFL students; these are related to selfefficacy, attitudes, learner autonomy, and teaching strategies. The literature varies considerably regarding how these challenges should be overcome, as most of the empirical evidence surrounded identifying the challenges and only speculated how these challenges could be surmounted. The four studies varied widely according to participant pools and methodologies used; and yet, the aforementioned, common themes were evident.

\subsection{Young EFL Learner Self-Efficacy}

The link between learner self-efficacy and academic performance is well documented but has been asserted as even more paramount within the context of language acquisition (Wang and Pape, 2007). Authors Wang and Pape (2007) cite that learners with a higher degree of self-efficacy are more persistent in solving language problems but highlighted that self-efficacy among young language learners is under-studied. Given the dearth of research regarding young EFL students and self-efficacy, the authors examined the relationship between selfefficacy and English language learning among three, Chinese students.

Self-efficacy is defined by Wang and Pape (2007) as "individuals' judgments of what they can do with the skills they possess, rather than the judgments of the skills themselves, and four major sources of self-efficacy information impact the level of self-efficacy: mastery or enactive experience, vicarious experience, social persuasion, and physiological or emotional state" (p. 364). Mastery and enactive experiences relate to past experiences of successes and failures, with the former raising self-efficacy and latter diminishing it, while vicarious experience refers to the observation of others' successes and failures (Wang and Pape, 2007). Social persuasion is the feedback received by students from peers and adults regarding the adequacy of language performance, and somatic information is the meaning given to the learning challenge (Wang and Pape, 2007).

Three, Chinese boys within the same academic context were qualitatively studied over a six-month period. The methodology included three audiotaped parental interviews, six hours of interviews with the children, fifteen videotaped observations of the participants at play, fifteen classroom observations, thirty follow-up, unstructured interviews, and a wide range of academic documents (Wang and Pape, 2007). A mix of Chinese and English were used during the study, and self-efficacy was judged according to persistence in accomplishing language tasks, self-awareness of English proficiency, and willingness to engage in language activities (Wang \& Pape, 2007). The study concluded that self-efficacy was mutable according to observed context. Moreover, vicarious self-efficacy was not able to be examined since there was no modeling available to students, and there was a strong influence of the particular task on the students' self-efficacy. The simpler the task, overall, the higher the degree of self-efficacy for the students (Wang \& Pape, 2007). Natural settings, such as the playground or cafeteria, seemed to boost student self-efficacy over classroom settings, though the bulk of observation took place in the classroom.

\subsection{Attitudes of EFL Higher Education Students}

Similar to self-efficacy, attitudes of language learners are posited to have a significant impact of learning success (Abu-Melhim, 2009). Attitudes diverge from self-efficacy, however, in several important ways. Attitudes are associations between objects and evaluations of those objects. Alternatively, attitudes are enduring evaluations of aspects of the social world that are stored within students' memories. Positive attitudes reveal the advantages of the object or, more specifically, the advantages of the subject's acknowledgement of the object's value (AbuMelhim, 2009). Negative attitudes are those that conversely reveal the disadvantages of the object (Abu-Melhim, 2009).

Attitudes have three components; these being affective or feelings about the attitude object, behavioural or a predisposition to act toward the attitude object in a specific way, and cognitive or beliefs specifically about the attitude object (Abu-Melhim, 2009). With respect to language specifically, the affecting attitudes are toward the language, toward learning the language, toward the teacher, and toward school in general. Abu-Melhim (2009) explored the attitudes of forty-five female EFL students in Jordan through qualitative interviews, concluding that 
the motivations for learning English significantly impacted the attitudes toward English language learning.

For example, many students believed that learning English was necessary to achieve their career goals, while others were merely pursuing the language because their parents were recommending they do so. Positive attitudes toward the language stemmed from believing it was important for becoming a global citizen, traveling and communicating cross-culturally. Only $64 \%$ of students cited that they "liked" the English language, and over $60 \%$ of participants had chosen the institution in which they were studying the language. A dominant theme existed that highlighted perceived necessity of English as influencing student attitudes.

\subsection{Teaching Strategies and EFL Learning}

Both Abu-Melhim and Wang and Pape highlighted that the teacher holds the power to support learner success, countering low self-efficacy and negative attitudes among learners, respectively. Gocer (2010) extends this point by citing that teaching strategies determine the techniques used by students during language acquisition, promoting listening, speaking, reading, and writing to varying degrees. For example, an educator that utilises visual and auditory tools will attract student attention, create dialogue environments, and assist in promoting the use of language in a natural environment.

The three, dominant types of teaching strategies are metacognitive, or those that involve knowing about learning and controlling it accordingly, cognitive, or those that transform the material, and social-affective, or those that involve the learner in direct communication (Gocer, 2010). The ability of the teacher to promote an environment in which learners experience all types of strategies to varying degrees is paramount, but non-native English-speaking teachers struggle with balancing instruction in this way (Gocer, 2010). By extension, a salient challenge faced by students is the non-native English-speaking status of teachers. Gocer (2010) investigated the relationship between teaching strategies and student success in several Turkish high schools, using qualitative interviews. The study concluded that most teachers use multi-media techniques in teaching and approach EFL instruction from an eclectic perspective. The author highlighted a possible dearth of discussion regarding the advantages of English language learning in class, citing that teachers did not examine the importance of English beyond the classroom to a sufficient extent. Alternative assessments and learner-centered instruction were rarely employed, and Gocer (2010) acknowledged that this is a considerable issue and would provide greater success among EFL students.

Porto (2007) corroborated Gocer's (2010) conclusions that lecture-and-drill methods of teaching and assessment were insufficient in promoting the success of EFL students. According to Porto (2007), students should be afforded a certain amount of independence during their learning, and this is particularly critical for language learners. Learner independence manifests in learner choice, which also boosts self-efficacy, learner reflection, which encourages introspection and a reevaluation of potentially poor attitudes toward the language. Porto (2007) examined the efficacy of learning diaries in promoting EFL learning among Argentinean college students learning English, concluding that the diaries were an invaluable teaching tool that boosted self-efficacy and countered negative attitudes among EFL learners.

\section{Discussion}

The literature suggests that the common challenges facing EFL learners of all ages are low self-efficacy, poor attitudes, and teaching strategies that do not afford them a high degree of independence. Three of the four studies (Abu-Melhim, 2009; Gocer, 2010; Porto, 2007) also suggested that non-native English-speaking teachers could inadvertently hinder the language acquisition of students, with Abu-Melhim (2009) asserting that these teachers were less likely to use alternative assessments and eclectic teaching strategies. The literature was limited by the cultural contexts in which the studies were conducted, but Jordan, Argentina, China, and Turkey are reflective of a broad, cultural context. The following section synthesises the research, affording particular respect to existing gaps and limitations while making recommendations for future studies.

\subsection{Self-Efficacy Problems}

For example, Wang and Pope's (2007) study asserted that all three participants were very aware that their English proficiency was low, reporting low self-efficacy levels for tasks that required a skill level greater than what they possessed. Vocabulary was a particular area of struggle for the participants, and past, negative experiences in English vocabulary tests significantly lowered the participants' self-efficacy levels. Emerging from Wang and Pape's (2007) study, however, was that areas in which the language content was situated was particularly critical. One of the participants, for instance, excelled at the game of chess, so language-related questions that highlighted chess boosted his self-efficacy levels considerably.

All three students in Wang and Pape's (2007) study had low self-efficacy with respect to social persuasion, as the participants' parents and teachers had given the children regular, derogatory comments regarding their English-speaking ability. Poor report cards and low-test scores that were not mediated by any verbal feedback or constructive criticism were particularly damaging to the students' self-efficacy, and, in turn, boost anxiety levels 
during language learning. Anxiety levels were among the most significant self-efficacy challengers, and there seemed to be a reciprocal relationship between anxiety and self-efficacy (Wang and Pape, 2007). Anxiety as being interconnected to self-efficacy was highlighted by Porto (2007) as well, with the author examining how teaching strategies boosting learner independence also reduce anxiety and boost self-efficacy.

Overall, self-efficacy as it relates to EFL success and learner autonomy is prevalent in all four studies. Accommodation theory asserts that language speakers will assume the roles they believe they have (Crystal, 2003), and self-efficacy then has the power to promote success not only in the classroom context but also during practical application of English in the proverbial real-world. If the classroom is a microcosm of environment in which students will apply their English knowledge, then a high degree of self-efficacy in the academic world will translate accordingly in professional and social contexts.

EFL students are in a unique position in that English is generally not entirely foreign to these learners; they have preconceived notions of grammar and vocabulary birthed from interactions with films and other media (Crystal, 2003). By extension, self-efficacy birthed from past experience with English that was positive is critical to EFL success. Moreover, creating opportunities for students to place English in a context with which they are familiar, such as relating it to a sport or otherwise culturally relevant subject, is paramount in boosting selfefficacy for young learners in particular.

\subsection{Negative Attitudes}

Abu-Melhim (2009), Porto (2007), and Wang and Pape (2007) all placed considerable emphasis on negative attitudes toward the English language as a salient obstacle in learning the language. Wang and Pape (2007) cited that not only do negative attitudes toward English impede a willingness to learn; they significantly lower selfefficacy among young learners. Identifying with an English-speaking community is paramount in non-English speaking nations for EFL students, and that identification should not be a coerced one. Promoting positive connections with English-speaking communities, be they virtual or otherwise, is then a valuable means of reducing negative attitudes and promoting self-efficacy.

Overall, the literature highlights attitudes towards English as malleable in the same way that self-efficacy can change over time (Abu-Melhim, 2009; Wang \& Pape, 2007). Abu-Melhim (2009) highlights that attitudes are internalized, however, and external influences in the academic environment can only affect attitudes among students insofar as they allow those effects to take place. Positive attitudes toward the language promote a willingness to be challenged and make mistakes, and these attitudes are birthed only from a genuine willingness to want to learn the language (Abu-Melhim, 2009).

The positive attitudes had by EFL students fuel an internal desire to acquire the language that, according to Abu-Melhim (2009), is not entirely controllable by teachers. The author asserts "it is crucial that students play their role. The role they play depends very much on their attitude towards the language itself and learning it. For instance, if you perceive the English language as not important, then to you, learning the language is a sheer waste of time. Whatever the work you produce is done out of routine" (p. 682). In essence, positive attitudes serve as a motivator, while negative attitudes serve as a considerable demotivator.

While the literature is clear on the link between negative attitudes, poor self-efficacy, and low levels of EFL success, it does not discuss from where, precisely, these attitudes emerge. Though Wang and Pape (2007) and Abu-Melhim (2009) highlight that teachers should aim to counter negative attitudes, neither author makes any concrete recommendations regarding how to do so beyond promoting membership in English-speaking communities. Only Gocer (2010) and Porto (2007) articulate how certain teaching strategies could potentially promote positive attitudes toward English.

\subsection{Teaching Strategies}

Both Gocer (2010) and Porto (2007) discuss various teaching strategies that promote EFL student success. According to Gocer (2010), teachers of English in Turkey are generally highly educated and pursue continuing education workshops regularly. In the classroom, however, they tend to opt for multimedia materials such as textbooks and CD-ROMs. Only 50\% of participants had an eclectic teaching style that varied methods such as presentation, findings, naturalistic settings, role-play, and collaborative learning (Gocer, 2010). Physical, classroom conditions were often insufficient, as were schedules for the teachers. Gocer (2010) writes that "the teachers who teach English in Turkey as a foreign language do not have the necessary competence in terms of the use of modern education strategies, utilization of materials and class applications, etc.... [T] he lessons are attempted to be conducted with a traditional teaching approach in which no environment is prepared for the efficient use of the target language" (p. 196). Consequently, Gocer (2010) concluded that none of the students exhibited interest in or desire to learn English effectively.

Students must be exposed to the advantages of English beyond the classroom, lest they will not be sufficiently motivated to acquire English. In a non-English speaking country, exposure to English-speaking communities and the use of teaching strategies that employ alternative assessments beyond lecture-and-drill, 
textbook-based learning is critical in catering to a wide population of learners (Gocer, 2010; Porto, 2007). Students learn differently, and Gocer's (2010) study indicates that a large portion of highly education EFL teachers in Turkish schools are only employing narrow teaching methods.

Porto (2007) discussed the insufficient nature of most EFL teaching strategies, corroborating Gocer's (2010) point that many teachers rely heavily on their instructional materials and do not seek out alternative methods for assessment and instruction. Both Porto (2007) and Gocer (2010) highlight that EFL teachers frequently do not have time to explore alternative teaching strategies, but Porto (2007) argues that fostering learner independence is paramount to the EFL classroom and can be done in any curricular context.

\subsection{Best Practices}

In order to help English Language Learners achieve their actual potential, it is essential to evaluate the best practices for testing and assessment. Currently, there is no national standardized method for assessing language proficiency in English Language Learning students. School districts utilize a variety of language proficiency tests and 13 states encourage the use of an oral native language assessment along with the English examination (Macswan and Rolstad, 2006).

English Language Learners also struggle on everyday classroom tasks that require a high level of proficiency in the English language. Most of the time these students do not have effective language supports to ease the test-taking process, such as an English-Spanish glossary with common vocabulary words (PennockRoman and Rivera, 2011). When faced with linguistically demanding test items, such as problem-solving tasks, English Language Learners have a difficult time because the focus relies on English language comprehension first rather than the content-related task.

There are multiple test accommodations that have proved successful in assisting English Language Learners and provided better practices in core content-specific areas. One example of a mathematics-specific assessment instrument that utilized effective testing accommodations for English Language Learners is the KeyMath-3 assessment (Alt et al., 2013). The mathematics-focused assessment implemented the use of language translation of test items to better determine ELL's mathematical knowledge. The research team translated test items into Spanish. During the examination, when a student incorrectly answers a KeyMath-3 question in English, the test item is re-administered in Spanish. Thus, the researchers can determine if the student does not understand the mathematical concept, or if the student's response reflects a problem with English language comprehension. As a result of this modification, there was a significant improvement in students' test scores. Researchers concluded that an English-only administration of the exam would not provide accurate evidence of English Language Learners' mathematical skills and that Spanish version is an appropriate accommodation for ELL students participating in high-stakes mathematics assessments (Alt et al., 2013).

Studies suggest incorporating additional supports that more accurately assist English Language Learners with regard to their specific classroom needs. One way to combat this overrepresentation of English Language Learners in special education is to hire a consultant to help referral team members more clearly define the difference between second language development and learning disability. The consultant is able to collaborate with teachers and administrators to provide neutral advice for placing a student in special education (Sanchez et al., 2010)

Early Response to Intervention (RTI) strategies also show promise in providing English Language Learners with improved early language development. Research indicates that when schools administer early phonological awareness strategies in the student's native language, such as Spanish word recognition and fluency assessments, this type of RTI is a better predictor of future performance in English literacy (Vanderwood, 2008). The improvement can be attributed to the fact that phonological awareness is not a language-specific skill. English Language Learners can apply these skills when they begin reading in English. The interventions identify students who are at risk for reading disabilities, but results show that this type of instruction help these ELL students "make substantial gains in reading" (Vanderwood, 2008, p. 1851).

Similarly, results from small-group reading interventions also see significant gains in both English and Spanish literacy performance among English Language Learners. One example of an effective intervention is Read Naturally, which is a daily, small reading group that focuses on repeated reading and progress monitoring. For the sake of making the intervention equitable for English Language Learners, the intervention materials are translated into Spanish. The daily repetitions of reading and frequent progress monitoring associated with this Response to Intervention technique help English Language Learners make considerable gains in oral fluency and literacy (Vanderwood, 2008). Consequently, districts that adopt an early literacy intervention can expect to increase early language development and reduce the number of students chosen for referral (Sanchez et al., 2010).

\section{Summary and Conclusion}

The literature clearly reveals that low self-efficacy, poor attitudes, and insufficient teaching strategies are the 
most significant challenges faced by EFL students. Gocer's (2010) study highlighted that teacher training is not a particular problem, though Abu-Melhim (2009) discussed that poor EFL teacher training has been emphasized in previous literature as formidable issues in the EFL profession. Limited resources, including time, were highlighted in both Gocer's (2010) and Porto's (2007) study as potential obstacles for EFL learners, but all four studies argued that self-efficacy, poor attitudes, and insufficient teaching strategies were common problems.

In order to serve English Language Learning students more appropriately, it is crucial to acknowledge the growing achievement gap between English Language Learners and their non-ELL peers. By addressing English Language Learners' specific linguistic needs, it is possible to reduce this gap in achievement and provide the best practice to assist English Language Learning students achieve to their ability. Rather than testing English Language Learners' cognitive ability based on their language proficiency level, assessments should first be adapted to more accurately provide individualized linguistic support. This means that support, including appropriate language and core content testing, should be implemented before a student is evaluated and placed in special education. By tackling the misdiagnosis before the placement into special education, ELL students can receive more suitable support to help them achieve their academic goals.

Schools must create support tools and utilize language resources to help teachers better provide for their linguistically diverse student population. School districts should observe the needs of the language learning population and stress the importance of early intervention strategies. Research indicates that early and frequent interventions can improve English Language Learners' performance. Districts need to more closely observe the definition of ability differences in the classroom to better classify their students with special needs (Artiles, Rueda, Salazar, \& Higareda, 2005). On the other hand, once a student has been referred and classified as a student with a learning disability related to language, that student should receive services befitting of their linguistic needs. It is true that "high-quality, effective instruction for all students in both general and special education could diminish the significance of overrepresentation" (Wolf et al., 2008).

\section{Recommendations for Future Research}

All of the literature had relatively small participant pools, under fifty participants, and was very specific to a geographic locale. Future research should focus on expanding the participant pools across national and cultural lines. The most salient areas of future research that are indicative of gaps in the reviewed literature are alternative assessments, possible limitations in training opportunities for EFL teachers, and possible roots of negative attitudes toward the English language among EFL students.

In short, the literature revealed the challenges that exist and, to a certain extent, articulated how those challenges might be surmounted. However, there was no discussion regarding how those obstacles, particularly low self-efficacy and poor attitudes, might be preemptively addressed. In student self-efficacy can be high from the beginning of EFL instruction in accordance with positive attitudes, then self-efficacy need not be boosted and poor attitudes need not be countered. Language learning is a complex, multidimensional field that demands constant, empirical attention (Crystal, 2003; Nunan, 1998). Given the global nature of the English language, filling the existing gaps in the literature is a critical charge of language professionals in the twenty-first century (Crystal, 2003).

The limited role of the educator highlighted by Abu-Melhim (2009) is at once interesting and unsettling, as a significant part of EFL success is charged to the student alone. If educators cannot, of their own volition, foster students' absorption of English, then optimum channels for facilitating English language learning must be uncovered and implemented into the EFL landscape. Future trends in research will undoubtedly focus on EFL, particularly as it is affected by globalisation. Students in non-English speaking nations will increasingly have more prior engagements with the English language due to the World Wide Web's influence and other technological innovations. Precisely how these forces will impact EFL remains to be seen, though the research implies that positive, prior experiences will boost self-efficacy while negative ones will diminish it (Wade and Pape, 2007).

Though this study only discussed the themes of four, recent studies, the shared nature of these themes is very telling. Future research should examine more of these shared themes, be they challenges or means of surmounting these challenges, as shared obstacles to English language acquisition will emerge as the language itself becomes more common around the world. Additional forces that may emerge as critical in the twenty-first century are the "new Englishes" that are evolving as the language combines with other tongues (Crystal, 2003), English acquisition during early childhood as opposed to later in life, and the advent of business English, relevant primarily in the professional context.

\section{References}

Abu-Melhim, A. (2009). Attitudes of Jordanian College Students towards Learning English as a Foreign Language. College Student Journal, 43(2), 682-700.

Alt, M., Arizmendi, G.D., Beal, C.R., \& Hurtado, J. (2013). The effect of test translation on the performance of 
second grade English learners on the KeyMath-3. Psychology in the Schools, 50(1), 27-36.

Crystal, D. (2003). English as a Global Language (2nd ed.). Cambridge, England: Cambridge University Press.

Gocer, A. (2010). A Qualitative Research on the Teaching Strategies and Class Applications of the High School Teachers Who Teach English in Turkey as a Foreign Language. Education, 131(1), 196-231.

Hasman, Melvia A. U.S. Department of State, Bureau of Educational and Cultural Affairs, Office of English Language Programs; Volume 39, Number1, Retrived August,1,2010.

Macswan, J., \& Rolstad, K. (2006). How language proficiency tests mislead us about ability: Implications for English Language Learner placement in special education. Teachers College Record, 108(11), 2304-2328.

Nunan, D. (1998). Second Language Learning and Teaching. Boston, MA: Heinle Publishing.

Pennock-Roman, M., \& Rivera, C. (2011). Mean effects of test accommodations for English Language Learners and non-English Language Learners: A meta-analysis of experimental studies. Educational Measurement: Issues and Practice, 30(3), 10-28.

Porto, M. (2007). Learning Diaries in the English as a Foreign Language Classroom: a Tool for Accessing Learners' Perceptions of Lessons and Developing Learner Autonomy and Reflection. Foreign Language Annals, 40(4), 672-703.

Sanchez, M.T., Parker, C., Akbayin, B., \& McTigue, A. (2010). Processes and challenges in identifying learning disabilities among students who are English Language Learners in three New York State Districts. Issues \& Answers (REL 2010-No. 085).

Vanderwood, M.L., \& Nam, J. (2008). Best practices in assessing and improving English Language Learners' literacy performance. Best Practices in School Psychology V (Vol. 5, 1847-1855). Bethesda, MD: NASP Publications.

Wang, C., \& Pape, S. J. (2007). A Probe into Three Chinese Boys' Self-Efficacy Beliefs Learning English as a Second Language. Journal of Research in Childhood Education, 21(4), 364-399. 